\title{
Spatial structure evolution of China railway network in the past century
}

\author{
YaLan Bai ${ }^{\text {a,b }}$, Haowen Yan ${ }^{\mathrm{a}, \mathrm{b}, *}$, Liang Zhou ${ }^{\mathrm{a}, \mathrm{b}}$ \\ ${ }^{a}$ Faculty of Geomatics, Lanzhou Jiaotong University, Lanzhou 730070, China,2531082635@qq.com, H. \\ Yan,haowen2010@gmail.com,L.Zhou,362572024@qq.com \\ ${ }^{b}$ Gansu Provincial Engineering Laboratory for National Geographic State Monitoring, Lanzhou 730070, China, \\ 553267213@qq.com,H.Yan,haowen2010@gmail.com,L.Zhou,362572014@qq.com \\ * Corresponding author: haowen2010@gmail.com
}

Keywords: Railway spatial pattern; Spatial statistical analysis; Nuclear density analysis

\begin{abstract}
:
With rapid development of big data technologies urbanization, the railway networks have also developed rapidly. The optimization of various aspects of railway networks has become more and more important with the shift of main contradictions in our society. With more than one hundred years of development of China railway network expansion, especially under the driving of "one belt and one road",China railway network is gradually mature. Up to now, the total length of China railways ranks second in the world, with a mileage of $127,000 \mathrm{~km}$. The spatial service scope of railway network has been further expanded and the structure has become more and more perfect, which has brought positive impacts on the development of all aspects of China.This paper analyzes the railways (lines) and stations (points) in five different development stages in China in the past 100 years,by means of spatial statistical and nuclear density analysis, based on which the spatial accessibility in different periods is calculated using cost distance analysis. The results show that the distribution of spatial pattern in Middle East region is higher than that in west region. The accessibility shows a significant difference between east and west, that the eastern region is superior to the western region. The difference of spatial pattern between the north and the south of Yangtze river is obvious. The overall spatial pattern presents a concentric structure, radiating from the North China region to the surrounding areas, and the reachable time from the North China region to the East China and Central South regions is gradually increasing.
\end{abstract}

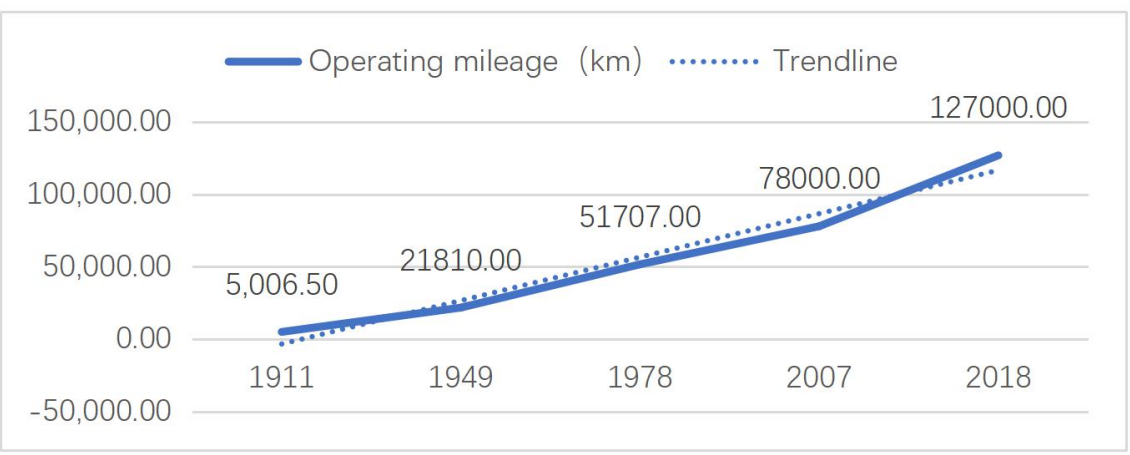

Fig.1 Analysis of the growth trend of China's railway mileage

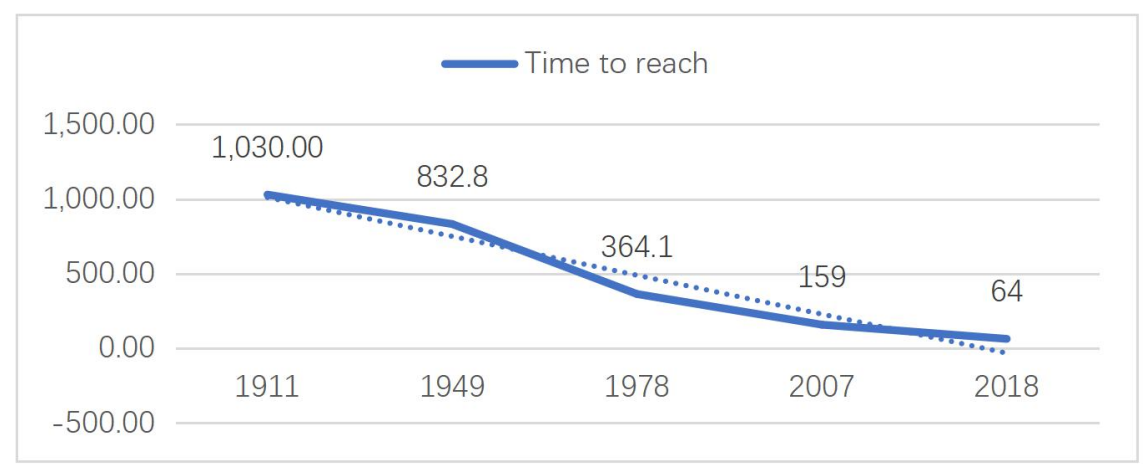

Fig.2 Trend analysis of China's railway arrival time

The conclusions of the study are as follows:

(1) The coverage region of China railways has been expanded.Since the completion of the first self-built railway (Beijing-Zhangiiakou Railway), the total length of China railways, has expanded from $5006.5 \mathrm{~km}$ in 1911 to $127,000 \mathrm{~km}$ 
in the end of 2017, which means it has increased by 253.6 times over 100 years, with an average annual growth rate of $1,1933.9 \mathrm{~km}$. The coverage of China Railways has expanded from 21 provinces in 1911 to all the provinces.

(2)The development of the time accessibility of the China railway network takes a favorable trend.The railway network has gradually improved,after more than 100 years' development.In 1911, the number of prefecture-level stations connected by the China railway network was only 62 . By $2000,83.6 \%$ of prefecture-level stations in China had been connected,and the number of connected ground-level stations reached 276. In 2018, more than 3066 ground-level stations have been connected,reaching time reduced from 1030 hours in 1911 to 64 hours in 2018. For example, the time from Beijing to Shanghai was shortened from more than 30 hours to 4 hours, saving about 8 times than before. It provides an important guarantee for the exchange of information between various regions in China.

(3)The overall expansion of China railway network presents an expansion from the coastal areas to inland areas. A detailed analysis of the seven major economic zones shows the expansion is from Bohai Economic Zone to other economic zones.After five stages of development, the sites in the eastern, central and western regions accounted for $28 \%, 33 \%$ and $38 \%$ respectively of the total. The spatial distribution of the sites in the eastern, central and western regions gradually became balanced, but the degree of perfection still differed. 